\title{
North Pacific Gyre Oscillation links ocean climate and ecosystem change
}

\author{
E. Di Lorenzo, ${ }^{1}$ N. Schneider, ${ }^{2}$ K. M. Cobb,${ }^{1}$ P. J. S. Franks, ${ }^{3}$ K. Chhak, ${ }^{1}$ A. J. Miller, ${ }^{4}$ \\ J. C. McWilliams, ${ }^{5}$ S. J. Bograd, ${ }^{6}$ H. Arango, ${ }^{7}$ E. Curchitser, ${ }^{7}$ T. M. Powell, ${ }^{8}$ \\ and P. Rivière ${ }^{9}$ \\ Received 29 November 2007; revised 31 January 2008; accepted 19 February 2008; published 30 April 2008.
}

[1] Decadal fluctuations in salinity, nutrients, chlorophyll, a variety of zooplankton taxa, and fish stocks in the Northeast Pacific are often poorly correlated with the most widely-used index of large-scale climate variability in the region - the Pacific Decadal Oscillation (PDO). We define a new pattern of climate change, the North Pacific Gyre Oscillation (NPGO) and show that its variability is significantly correlated with previously unexplained fluctuations of salinity, nutrients and chlorophyll. Fluctuations in the NPGO are driven by regional and basin-scale variations in wind-driven upwelling and horizontal advection - the fundamental processes controlling salinity and nutrient concentrations. Nutrient fluctuations drive concomitant changes in phytoplankton concentrations, and may force similar variability in higher trophic levels. The NPGO thus provides a strong indicator of fluctuations in the mechanisms driving planktonic ecosystem dynamics. The NPGO pattern extends beyond the North Pacific and is part of a global-scale mode of climate variability that is evident in global sea level trends and sea surface temperature. Therefore the amplification of the NPGO variance found in observations and in global warming simulations implies that the NPGO may play an increasingly important role in forcing global-scale decadal changes in marine ecosystems. Citation: Di Lorenzo, E., et al. (2008), North Pacific Gyre Oscillation links ocean climate and ecosystem change, Geophys. Res. Lett., 35, L08607, doi:10.1029/2007GL032838.

\section{Introduction}

[2] Indices of large-scale climate variability such as the Pacific Decadal Oscillation (PDO) [Mantua et al., 1997]

\footnotetext{
${ }^{1}$ School of Earth and Atmospheric Sciences, Georgia Institute of Technology, Atlanta, Georgia, USA.

${ }^{2}$ International Pacific Research Center and Department of Oceanography, School of Ocean and Earth Science and Technology, University of Hawaii at Manoa, Honolulu, Hawaii, USA.

${ }^{3}$ Scripps Institution of Oceanography, University of California, San Diego, La Jolla, California, USA.

${ }^{4}$ CASPO Division, Scripps Institution of Oceanography, University of California, San Diego, La Jolla, California, USA.

${ }^{5}$ Institute of Geophysics and Planetary Physics and Department of Atmospheric and Oceanic Sciences, University of California, Los Angeles, California, USA.

${ }^{6}$ Southwest Fisheries Science Center, NMFS, NOAA, Pacific Grove, California, USA.

${ }^{7}$ Institute of Marine and Coastal Sciences, Rutgers University, New Brunswick, New Jersey, USA.

${ }^{8}$ Department of Integrative Biology, University of California, Berkeley, California, USA.

${ }^{9}$ LEMAR, IUEM Thechnopole Brest-Iroise, Plouzane, France.
}

Copyright 2008 by the American Geophysical Union. 0094-8276/08/2007GL032838 and the El Niño Southern Oscillation (ENSO) are often invoked to explain physical and biological fluctuations in the Northeast Pacific Ocean [Lynn et al., 1998; Lavaniegos and Ohman, 2003, 2007; McGowan et al., 1998]. Changes in the magnitude and sign of the indices have been correlated with variations in biological properties such as zooplankton displacement volume [Roemmich and McGowan, 1995] and fish populations [Hare et al., 1999]. Particularly dramatic physical and biological excursions occurred during the 1976-77 change in the PDO [Hare and Mantua, 2000] [McGowan et al., 2003] and during the 1997-99 ENSO cycle [Peterson and Schwing, 2003]. However, the mechanisms coupling fluctuations in the PDO to changes in biological variables remain unclear. Furthermore, both the PDO and ENSO fail to explain decadal variations of key oceanic variables in the North Pacific, particularly the prominent salinity and nutrient variations seen in the California Cooperative Oceanic Fisheries Investigations (CalCOFI; www.calcofi.org) records from 1949 to 2005 [Schneider et al., 2005; Di Lorenzo et al., 2005].

[3] In this study, we present evidence that interannual and decadal variations of salinity, nutrient upwelling, and surface chlorophyll-a (Chl-a) in the Northeast Pacific are associated with fluctuations in a climate pattern that we term the North Pacific Gyre Oscillation (NPGO). We use the term NPGO because its fluctuations reflect changes in the intensity of the North Pacific gyre circulations.

\section{Methods}

[4] The PDO and NPGO modes of climate variability emerge from analyses of Northeast Pacific sea-surface temperature anomalies (SSTa) and sea-surface height anomalies (SSHa) over the region $\left(180^{\circ} \mathrm{W}-110^{\circ} \mathrm{W}\right.$; $25^{\circ} \mathrm{N}-62^{\circ} \mathrm{N}$ ). Using empirical orthogonal function (EOF) techniques, these oceanic fields are each decomposed into a set of independent/uncorrelated spatial modes (the EOFs) whose temporal fluctuations are given by the corresponding Principal Components (PCs). The first EOF and PC spatial and temporal pattern explain the highest fraction of the variance; subsequent sets of EOFs and PCs explain successively less variance of the field. The PDO climate pattern emerges as the first EOF/PC of both SSTa and SSHa, while the NPGO represents the second EOF/PC. Because the first PCs of SSTa and SSHa are highly correlated $(\mathrm{R} \approx 0.85)$, we define a PDO index as the first PC of SSHa and the NPGO index as the second PC of SSHa (Figure 1). (The NPGO index can be downloaded at http://www.ocean3d.org/npgo.) The NPGO index closely tracks the second PC of SSTa, which is also known as the "Victoria Mode" index [Bond et 
al., 2003], although the NPGO index exhibits more prominent low-frequency fluctuations than the "Victoria Mode". Following these definitions the NPGO is statistically independent of the PDO. We also verify that these modes are distinct and separate in both SSHa and SSTa by performing

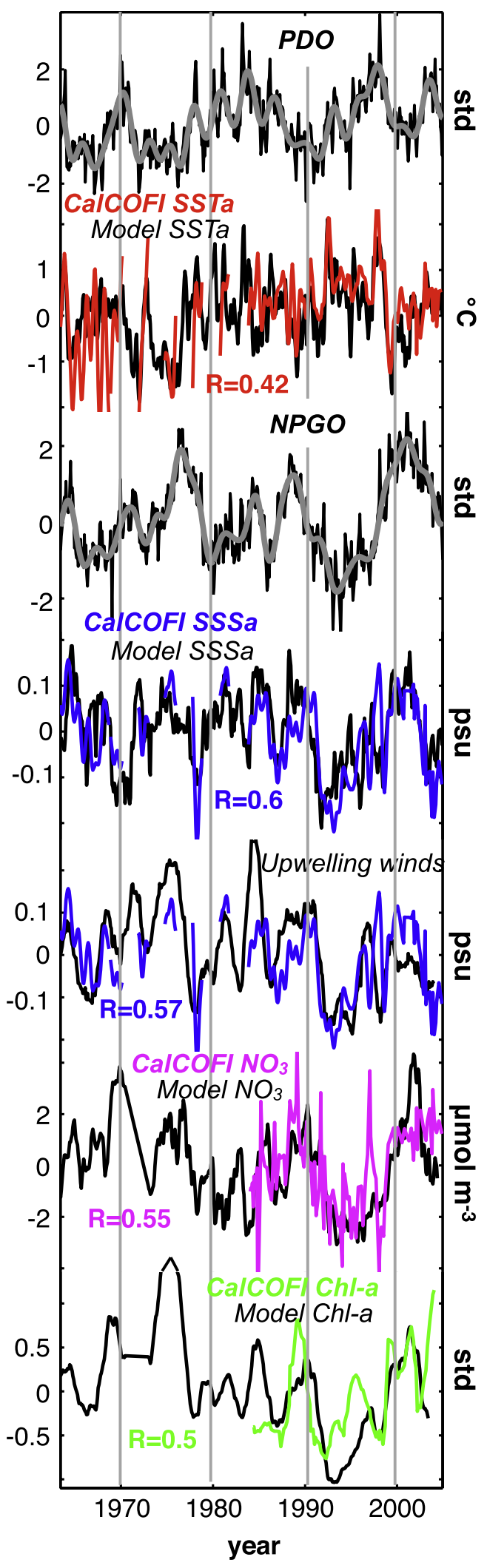

Table 1. Correlations of the Model PDO and NPGO Indices With CalCOFI Data ${ }^{\mathrm{a}}$

\begin{tabular}{lcc}
\hline & PDO & NPGO \\
\hline $\mathrm{SSTa}$ & $\mathbf{0 . 4 4}$ & 0.29 \\
$\mathrm{SSSa}$ & 0.06 & $\mathbf{0 . 4 2}$ \\
$\mathrm{Chl}-\mathrm{a}$ & 0.21 & $\mathbf{0 . 4 7}$ \\
$\mathrm{NO}_{3}$ & 0.26 & $\mathbf{0 . 5 1}$ \\
$\mathrm{PO}_{4}$ & 0.19 & $\mathbf{0 . 3 5}$ \\
$\mathrm{SiO}_{4}$ & 0.31 & $\mathbf{0 . 5 3}$ \\
$\mathrm{O}_{2}$ & 0 & $\mathbf{- 0 . 5 0}$ \\
\hline
\end{tabular}

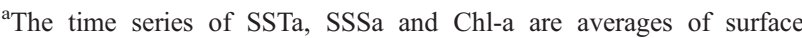
observations from the CalCOFI program in the Southern California Current. The nutrient time series are spatial averages of samples from $150 \mathrm{~m}$ depth Bold numbers indicate correlations significant at the $95 \%$ level or higher.

an analysis of the eigenvalues spectrum from the EOF decompositions [North et al., 1982].

[5] We investigate the NPGO and PDO climate patterns and their underlying dynamics using a high-resolution model of the Northeast Pacific Ocean. The Regional Ocean Modeling System (ROMS) [Shchepetkin and McWilliams, 2005 ] is used in a nested configuration representing the Northeast Pacific $\left(180^{\circ} \mathrm{W}-110^{\circ} \mathrm{W} ; 25^{\circ} \mathrm{N}-62^{\circ} \mathrm{N}\right)$. The model grid has $15 \mathrm{~km}$ average horizontal resolution and 30 vertical terrain-following layers. The model is forced with surface wind stresses and heat fluxes from the US National Center for Environmental Prediction (NCEP) [Kalnay et al., 1996] over the period 1950-2004. The SST boundary condition includes a time-dependent relaxation to SST reanalysis [Smith and Reynolds, 2004] with a timescale $\approx$ 1 month to account for errors in the NCEP surface heat fluxes [Josey, 2001]. The SSS boundary condition is a corrected monthly climatology of freshwater flux, which ensures that changes in salinity on periodicities larger than the seasonal cycle are only controlled by changes in ocean advection. Chl-a and $\mathrm{NO}_{3}$ are modeled with a simple nutrient-phytoplankton-zooplankton-detritus (NPZD) ecosystem model [Powell et al., 2006].

[6] The numerical model has significant skill in reconstructing the regional oceanic biological and physical conditions between 1950-2004, and tracks the observed temporal fluctuations of SSTa, sea surface salinity anomaly (SSSa), Chl-a, and subsurface $150 \mathrm{~m} \mathrm{NO}_{3}$ in the CalCOFI region (Figure 1; all $>95 \%$ significance). The significance of the correlations for the monthly-averaged timeseries is estimated from the Probability Distribution Functions

Figure 1. PDO and NPGO compared to the model and CalCOFI observations. The PDO and NPGO indices (black) are plotted in standard deviation units with their 2 yr lowpass filtered time series (grey). All other time series are spatial averages from the Southern California Current System model (black) or data (color). Correlations of raw monthly data between the model and data are given below each time series pair in color. All correlations are significant at the $95 \%$ level or greater. The nitrate timeseries uses samples from $150 \mathrm{~m}$. The Chl-a anomaly data have been smoothed with a 2 yr running average, and normalized by their standard deviation. The upwelling winds are calculated from NCEP reanalysis data, smoothed with a 2 yr running average, and standardized to psu units for comparison to CalCOFI SSSa. Positive winds are directed equatorward, implying upwelling favorable conditions. 

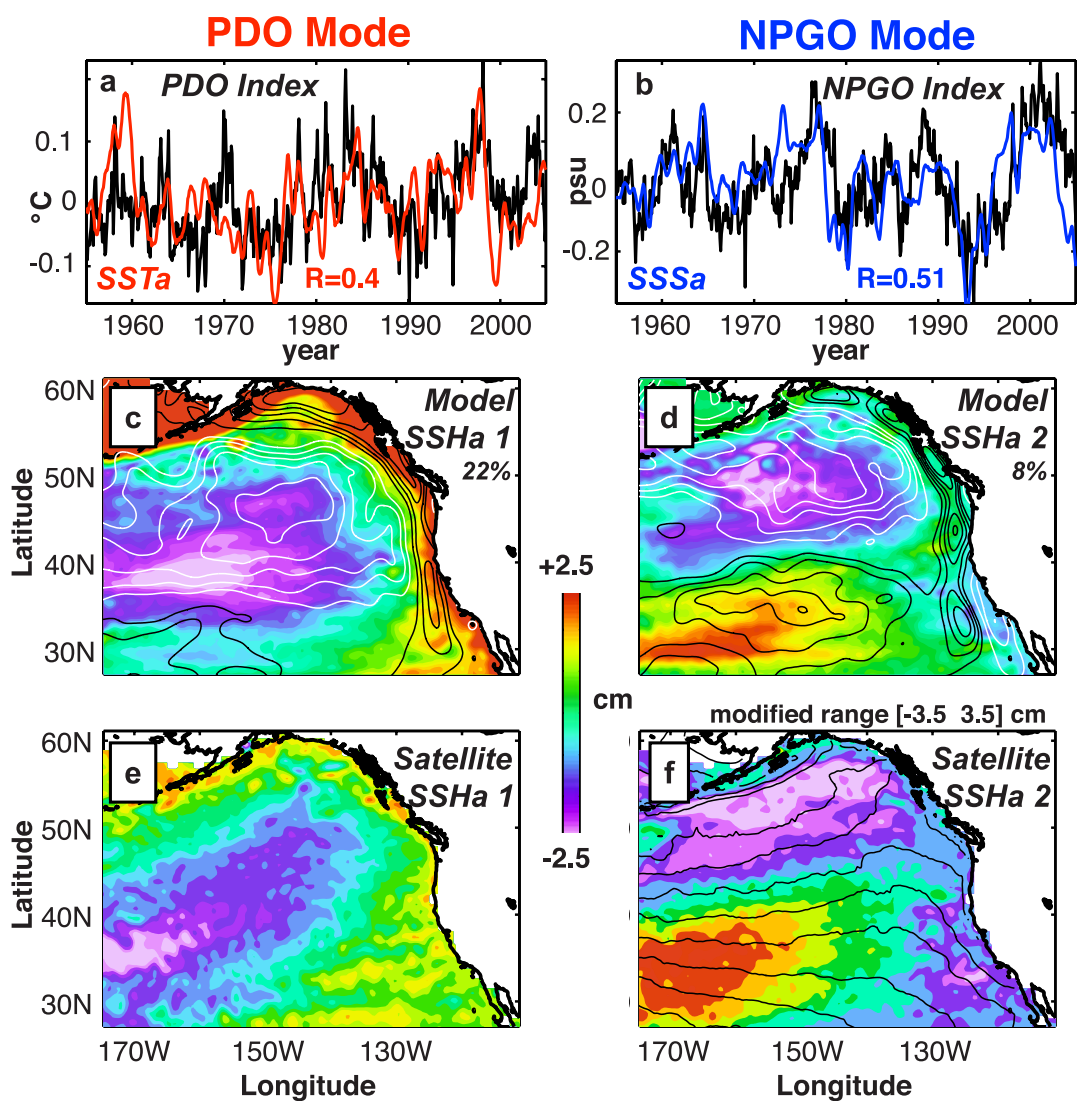

cm

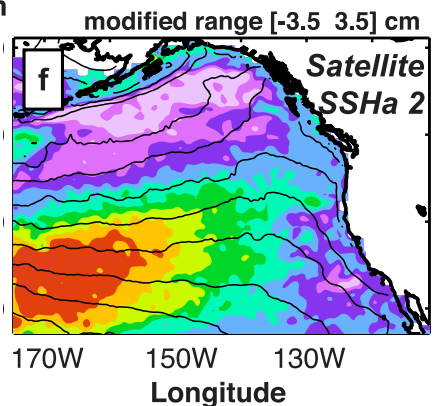

Figure 2. PDO and NPGO patterns from model and data. (a) Time series of La Jolla Scripps Pier $\left(32^{\circ} \mathrm{N}, 117^{\circ} \mathrm{W}\right) \mathrm{SSTa}$ (red) compared to the PDO index (correlation $\mathrm{R}=0.4 ; 99 \%$ significance), defined as the first PC of model SSHa (black). (b) Time series of La Jolla Scripps Pier SSSa (blue) compared to the NPGO index (correlation R $=0.51,99 \%$ significance), defined as the second PC of model SSHa (black). Thin black lines are 2 yr running averages of the model PCs. The SSTa and SSSa records are detrended and a 12 months running mean is applied. (c, d) Regression maps of model PDO and NPGO indices with the model SSHa. The white (black) contours indicate regions of positive (negative) wind stress curl (Ekman upwelling) as inferred from a regression of the model PCs with the NCEP wind stress curl. The \% variance accounted for by each regression map is indicated. (e, f) Regression maps of the model PDO and NPGO indices with satellite altimeter data gathered between 1993-2004. The colour range is modified to [ $-3.53 .5]$ in Figure $2 \mathrm{f}$ to properly display the map (black contours are satellite/drifter-derived mean dynamic height [Niiler et al., 2003]).

(PDFs) of the correlation coefficient of two red noise timeseries that possessed same autoregression coefficients as the original signals. The PDFs are computed numerically by generating 3000 realizations of the correlation coefficient of two random red noise timeseries.

\section{Results and Discussion}

[7] Consistent with previous observational analyses we find that the PDO is the dominant mode of variability of monthly SSTa and SSHa in the ocean model: the first EOF accounts for $34 \%$ of the variance of SSTa and $22 \%$ of the variance of SSHa. The NPGO mode - the second EOF of SSTa and SSHa - explains $22 \%$ and $8 \%$ of the variance of those fields, respectively. However, while the PDO index is significantly correlated with the observed CalCOFI SSTa record (Figure 1 and Table 1), only the NPGO is significantly correlated with observed fluctuations of CalCOFI SSSa, Chl-a, and subsurface $\mathrm{NO}_{3}, \mathrm{PO}_{4}, \mathrm{SiO}_{4}$ and $\mathrm{O}_{2}$ concentrations (Figure 1 and Table 1). The coastal timeseries of SSTa and SSSa collected at the La Jolla Scripps Pier $\left(32^{\circ} \mathrm{N}, 117^{\circ} \mathrm{W}\right)$, which are continuous in time, show similar correlations to the PDO and NPGO respectively (Figure 2). These correlations speak to the different dynamics underlying the two indices.

[8] In the California Current System (CCS) the NPGO reflects changes in wind stress, in particular the winds that force coastal upwelling. This is evident in the strong correlation of the NPGO index with CalCOFI SSSa over the past 50 years: observed fluctuations in SSSa are very strongly correlated with alongshore wind stress, the driver of coastal upwelling in the CalCOFI region (Figure 1). These results strongly support the use of the NPGO as the primary indicator of upwelling strength, nutrient fluxes, and the potential for ecosystem change in the CalCOFI region.

[9] Changes in nutrient fluxes drive fluctuations in modeled Chl-a that are highly correlated to observed Chl-a. In the model the primary mechanism for change of the Chl-a is through variations in wind-driven vertical nutrient flux. Therefore, the high correlation of modeled and observed Chl-a (Figure 1) supports the hypothesis that fluctuations in phytoplankton biomass in the CalCOFI region are primarily driven by changes in wind-driven upwelling correlated with 

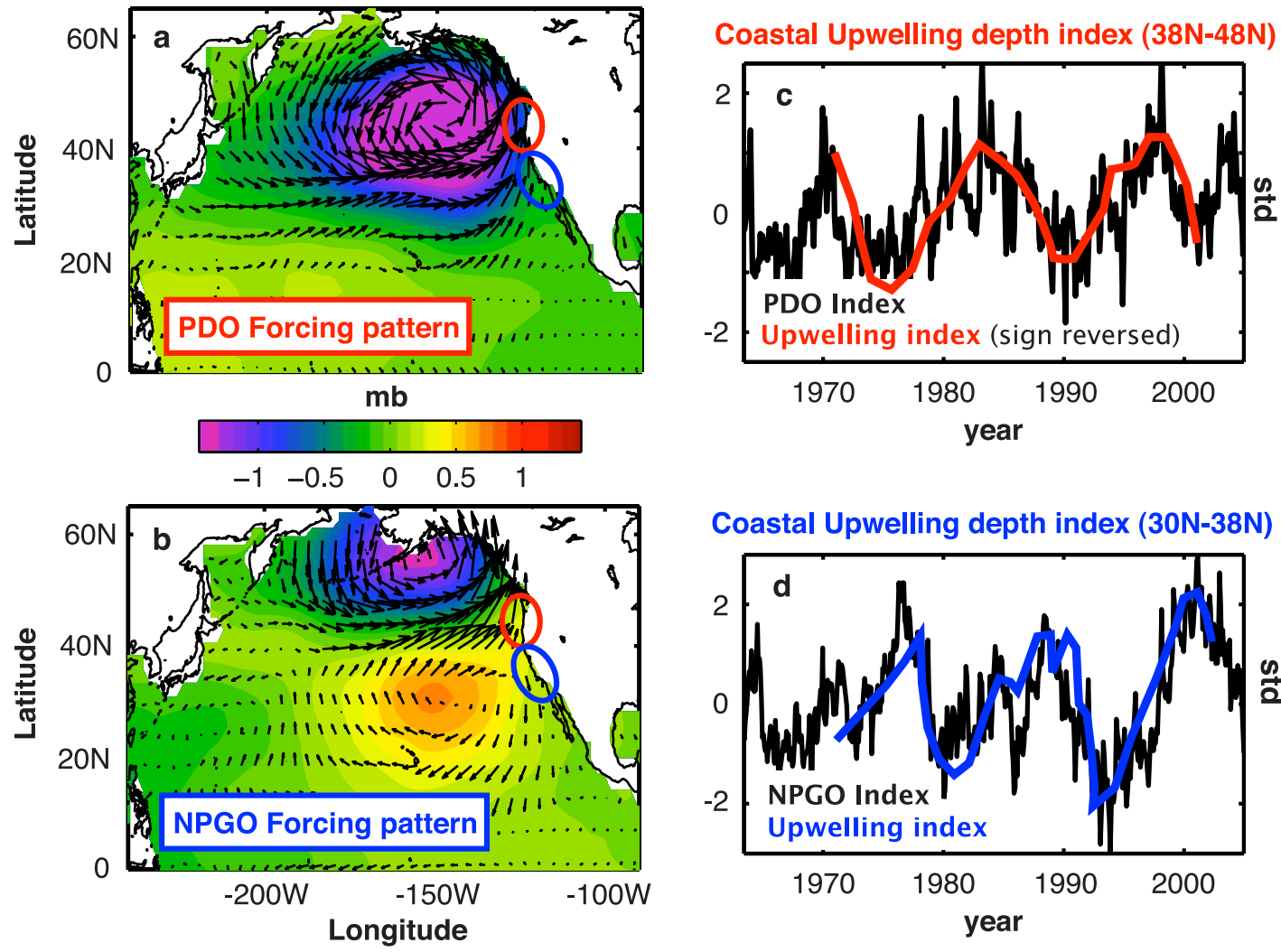

Coastal Upwelling depth index (30N-38N)

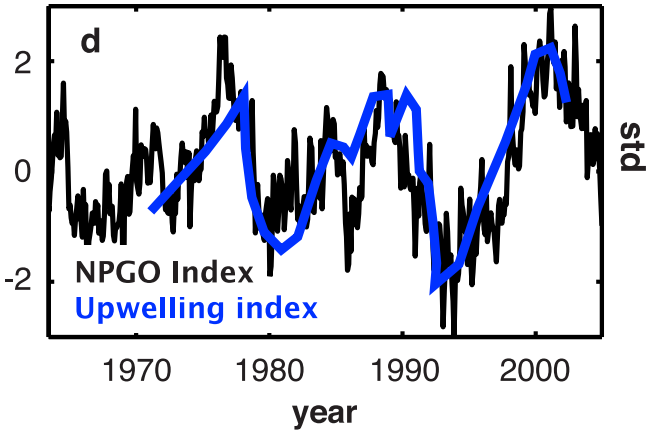

Figure 3. Atmospheric forcing patterns of the PDO and NPGO modulate decadal changes in coastal upwelling. Regression maps of (a) PDO and (b) NPGO indices with NCEP windstress vectors and sea level pressure (color scale). (c) Coastal upwelling depth index from inverse model calculations [Chhak and Di Lorenzo, 2007] averaged from 38N to 48N (area denoted by red circle in Figures $3 \mathrm{a}$ and $3 \mathrm{~b}$ ) compared to PDO index. (d) Coastal upwelling depth index averaged from $30 \mathrm{~N}$ to $38 \mathrm{~N}$ (area denoted by blue circle in Figures $3 \mathrm{a}$ and $3 \mathrm{~b}$ ) compared to NPGO index. A positive upwelling index implies a deeper upwelling cell.

the NPGO. This "bottom-up" forcing is consistent with the conclusions from previous analyses of fish catch data and satellite-derived Chl-a [Ware and Thomson, 2005; Rykaczewski and Checkley, 2008], and underscores the need to better understand the influences of physically forced nutrient fluxes on higher trophic levels in the ocean.

[10] Fluctuations of the PDO have often been implicated in major physical-biological regime shifts in the North Pacific (e.g. 1976, 1999) [Hare and Mantua, 2000; Lavaniegos and Ohman, 2003]; however, the NPGO mode shows equally dramatic transitions during these periods (Figure 1). Indeed these recent major ecosystem regime shifts have occurred when the PDO and NPGO show strong, simultaneous, and opposite sign reversals (Figure 1). The alternating importance between the PDO and NPGO fluctuations on decadal timescales may explain why some changes in the sign of the PDO index did not correspond to dramatic ecological shifts. Diagnosing and predicting ecosystem climate variability in the North Pacific will depend on determining the effects of the phase relationship between fluctuations of the PDO and NPGO modes.

[11] The regional spatial patterns of the PDO and NPGO in the SSHa are distinct, and give further insights into the dynamics they represent (Figure 2). Assuming that the SSHa reflect changes in the geostrophic flow, the PDO mode shows a single large gyre north of $25^{\circ} \mathrm{N}$ and an anomalously strong poleward flow along the entire coast from $25^{\circ} \mathrm{N}$ to $55^{\circ} \mathrm{N}$ (Figure 2c). This flow is forced by predominantly downwelling conditions at the coast; a positive PDO results in a strengthening of the Alaskan Gyre but a weakening of the California Current. In contrast, the NPGO mode in its positive phase shows a pair of counterrotating gyres that reflect the gyre-scale mean geostrophic circulation inferred from satellite [Niiler et al., 2003] (Figure 2d). The northernmost Alaskan Gyre is separated from the more southerly Subtropical Gyre by the North Pacific Current (NPC), which flows eastward along $\sim 40^{\circ} \mathrm{N}$. The NPC bifurcates at the coast, flowing northward to form the Alaskan Coastal Current, and southward to form the California Current. When positive, the NPGO represents an intensification of the geostrophic circulation, that is a strengthening of the NPC, and (in contrast to the PDO) an increase in the transport of both the Alaskan Coastal Current and California Current (Figure 2). This intensification of both the subpolar and subtropical gyres is driven in the model by open-ocean wind stress curl anomalies (Figures $2 \mathrm{c}$ and $2 \mathrm{~d}$, contour lines) and by variations in wind-driven coastal upwelling. The spatial structure of the wind anomalies is consistent with the positive phase of the North Pacific Oscillation (NPO) [Walker and Bliss, 1932], which is a dominant mode of variability in atmospheric sea level pressure. This suggests that the NPGO is the oceanic expression of the atmospheric NPO. When the NPGO is positive, the associated changes in wind forcing (Figure 3) 

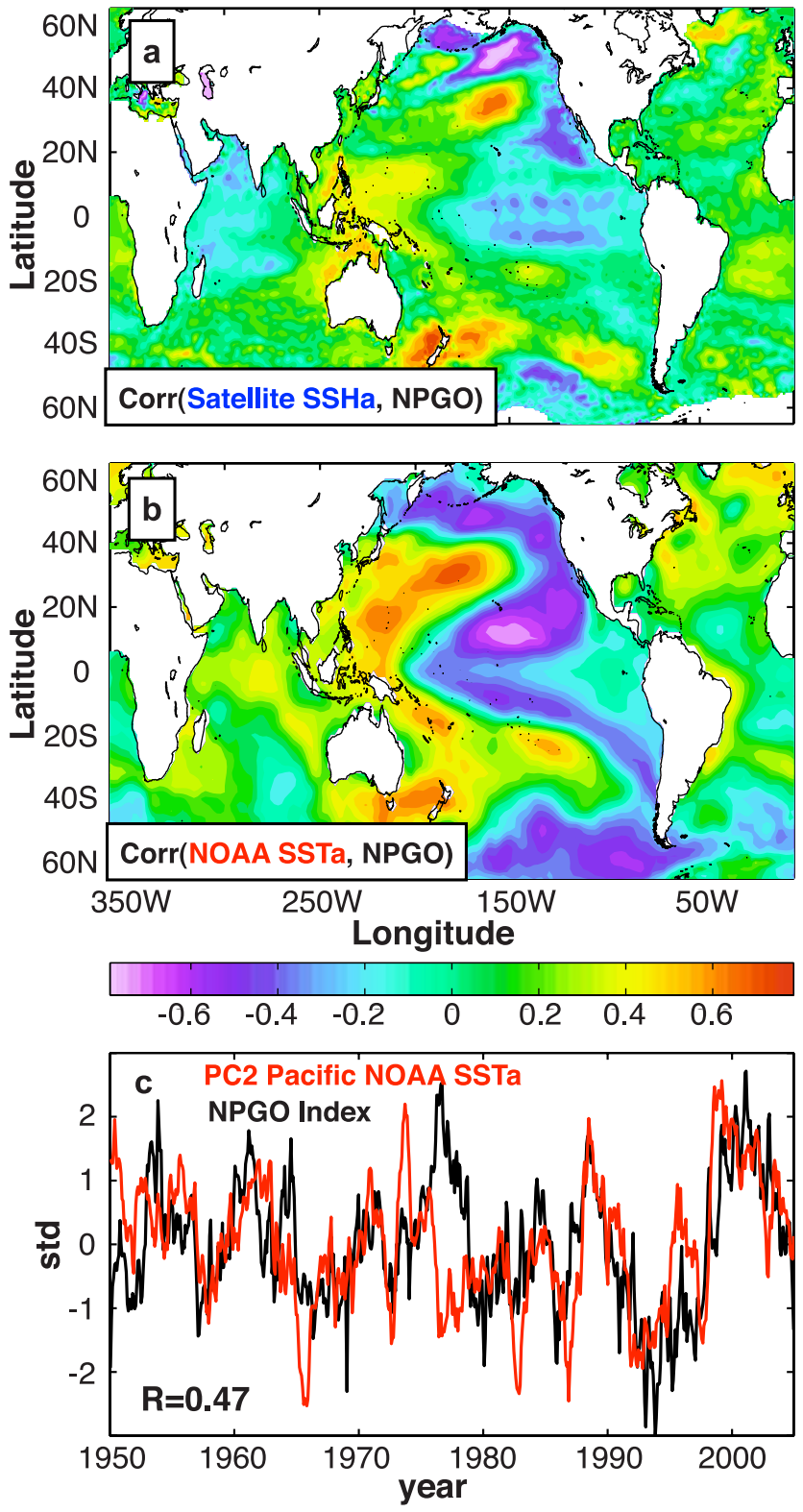

Figure 4. Global patterns of the NPGO in the SSHa and SSTa fields. Correlation map of the model NPGO index with (a) satellite altimetry and (b) SSTa reanalysis during the period 1993-2004. The double-gyre structure of the Northeastern Pacific NPGO is apparent in both maps, and is part of a global pattern that is symmetric across the equator, which suggest that coupled dynamics in the tropics are involved in the dynamics of the NPGO. The correlation between the NPGO index and the second PC of Pacific $\mathrm{SSTa}$ (c) is $\mathrm{R}=0.47$ and is significant at the $99 \%$ level.

create upwelling-favorable conditions in the California Current and Alaskan Gyre, but downwelling conditions in the Subtropical Gyre and the Alaskan Coastal Current. However, upwelling variability along the Northeast Pacific coast is strongly correlated with NPGO only south of $38^{\circ} \mathrm{N}$; farther north, upwelling is more strongly controlled by changes in alongshore winds correlated with the PDO (Figure 3), as indicated by previous findings [Chhak and Di Lorenzo, 2007].
[12] The PDO and NPGO spatial patterns found in our model are clearly seen in observations such as satellitederived sea level data (Figures 2e and 2f). Over the period 1993-2005 a regression of the model-reconstructed PDO and NPGO indices with the merged satellite altimeter analysis from AVISO (http://www.jason.oceanobs.com/) reproduces the spatial patterns of the modeled NPGO and PDO modes (Figure 2). Interestingly, both the satellite regression maps and our model show that the NPGO amplitude was larger than the PDO amplitude during the last decade, a finding confirmed by independent analyses of both in situ and other satellite data [Cummins and Freeland, 2007]. This recent strengthening of the NPGO mode is also revealed by the fact that the second EOF of SSTa (which is an expression of the NPGO and is referred to in the literature as the "Victoria" mode) explains more wintertime North Pacific SSTa variance than the PDO pattern during the 1990-2002 period [Bond et al., 2003].

[13] The NPGO spatial pattern extends well beyond the Northeast Pacific and CalCOFI regions, and is part of a global climate pattern. This is apparent in correlations of the NPGO index with global SSTa reanalysis [Smith and Reynolds, 2004] and satellite SSHa (http://www.jason.oceanobs.com/) (Figure 4). The global NPGO SSHa pattern explains a trend uncovered in global sea-level data during the period 1990-2000 [Kohl et al., 2007], when the NPGO index shows a near monotonic increase (Figure 4c). The NPGO SSTa pattern corresponds to the second EOF of Pacific SSTa that is isolated in both observations and global ocean model integrations [Doney et al., 2007]. Indeed, the NPGO index shows a significant correlation with the second PC of Pacific SSTa (Figure 4c). The SSTa NPGO spatial pattern is strongly symmetric across the equator, suggesting that tropical coupled dynamics are involved in forcing the NPGO fluctuations. The large-scale structure of the NPGO pattern also suggests that its underlying dynamics drive spatially coherent decadal fluctuations in ecosystems across the Pacific Ocean.

[14] The observed strengthening of the NPGO mode since 1993 reported here and in other studies [Cummins and Freeland, 2007; Bond et al., 2003; Douglass et al., 2006] may represent a response to anthropogenic forcing and global warming. This hypothesis is supported by preliminary analyses of climate projections from the GFDL 2.0 coupled climate model (experiments GFDL CM2.0, 20C3M and GFDL CM2.0, SRES A2), which show an amplification of the NPGO variance by $38 \%$ and a reduction of the PDO variance by $58 \%$ between the periods 1900 2000 and 2000-2100. If true, we expect the dynamics underlying the NPGO to play an increasingly important role in Pacific-wide ecosystem transitions in coming decades. Further work is in progress to explore the utility and implications of the NPGO for understanding past, and predicting future global climate and ecosystem change.

[15] Acknowledgments. We acknowledge the support of the National Science Foundation grants OCE-0550266, GLOBEC-0606575, OCE-0452654, OCE-0452692, CCS-LTER, NASA NNG05GC98G, DOE DE-FG02-04ER63857 and the French CNRS CYBER-LEFE Programme. We also thank Mark Ohman and Patrick Cummins for their discussions. A special thanks to Tessa Di Lorenzo for motivating and inspiring this work. 


\section{References}

Bond, N. A., J. E. Overland, M. Spillane, and P. Stabeno (2003), Recent shifts in the state of the North Pacific, Geophys. Res. Lett., 30(23), 2183 , doi:10.1029/2003GL018597.

Chhak, K., and E. Di Lorenzo (2007), Decadal variations in the California Current upwelling cells, Geophys. Res. Lett., 314, L14604, doi:10.1029/ 2007GL030203.

Cummins, P. F., and H. J. Freeland (2007), Variability of the North Pacific Current and its bifurcation, Prog. Oceanogr., 75(5), 253-265.

Di Lorenzo, E., et al. (2005), The warming of the California Current System: Dynamics and ecosystem implications, J. Phys. Oceanogr., 35(3), $336-362$

Doney, S. C., et al. (2007), Mechanisms governing interannual variability of upper-ocean temperature in a global ocean hindcast simulation, J. Phys. Oceanogr., 37(7), 1918-1939.

Douglass, E., D. Roemmich, and D. Stammer (2006), Interannual variability in northeast Pacific circulation, J. Geophys. Res., 111, C04001, doi:10.1029/2005JC003015.

Hare, S. R., and N. J. Mantua (2000), Empirical evidence for North Pacific regime shifts in 1977 and 1989, Prog. Oceanogr., 47(2-4), 103-145.

Hare, S. R., et al. (1999), Inverse production regimes: Alaska and West Coast Pacific salmon, Fisheries, 24(1), 6-14.

Kalnay, E., et al. (1996), The NCEP/NCAR 40-year reanalysis project, Bull. Am. Meteorol. Soc., 77(3), 437-471.

Kohl, A., et al. (2007), Interannual to decadal changes in the ECCO global synthesis, J. Phys. Oceanogr., 37(2), 313-337.

Josey, S. A. (2001), A comparison of ECMWF, NCEP-NCAR, and SOC surface heat fluxes with moored buoy measurements in the subduction region of the northeast Atlantic, J. Clim., 14, 1780-1789.

Lavaniegos, B. E., and M. D. Ohman (2003), Long-term changes in pelagic tunicates of the California Current, Deep Sea Res., Part II, 50(14-16), $2473-2498$.

Lavaniegos, B. E., and M. D. Ohman (2007), Coherence of long-term variations of zooplankton in two sectors of the California Current System, Prog. Oceanogr., 75(1), 42-69.

Lynn, R. J., et al. (1998), The state of the California Current, 1997-1998: Transition to El Nino conditions, Calif. Coop. Oceanic Fish. Invest. Rep. 39, pp. 25-49, La Jolla, Calif.

Mantua, N. J., et al. (1997), A Pacific interdecadal climate oscillation with impacts on salmon production, Bull. Am. Meteorol. Soc., 78(6), 10691079.

McGowan, J. A., et al. (1998), Climate-ocean variability and ecosystem response in the northeast Pacific, Science, 281(5374), 210-217.

McGowan, J. A., et al. (2003), The biological response to the 1977 regime shift in the California Current, Deep Sea Res., Part II, 50(14-16), $2567-$ 2582.

Niiler, P. P., N. A. Maximenko, and J. C. McWilliams (2003), Dynamically balanced absolute sea level of the global ocean derived from near-surface velocity observations, Geophys. Res. Lett., 30(22), 2164, doi:10.1029/ 2003GL018628
North, G. R., et al. (1982), Sampling errors in the estimation of empirical orthogonal functions, Mon. Weather Rev., 110(7), 699-706.

Peterson, W. T., and F. B. Schwing (2003), A new climate regime in northeast Pacific ecosystems, Geophys. Res. Lett., 30(17), 1896, doi:10.1029/ 2003GL017528.

Powell, T. M., C. V. W. Lewis, E. N. Curchitser, D. B. Haidvogel, A. J. Hermann, and E. L. Dobbins (2006), Results from a three-dimensional, nested biological-physical model of the California Current System and comparisons with statistics from satellite imagery, J. Geophys. Res., 111, C07018, doi:10.1029/2004JC002506.

Roemmich, D., and J. McGowan (1995), Climatic warming and the decline of zooplankton in the California current, Science, 267(5202), 13241326.

Rykaczewski, R. R., and D. M. Checkley (2008), Influence of ocean winds on the pelagic ecosystem in upwelling regions, Proc. Natl. Acad. Sci., 105(6), 1965-1970, 10.1073/pnas.0711777105.

Schneider, N., et al. (2005), Salinity variations in the Southern California Current, J. Phys. Oceanogr., 35(8), 1421-1436.

Shchepetkin, A. F., and J. C. McWilliams (2005), The regional oceanic modeling system (ROMS): A split-explicit, free-surface, topography-following-coordinate oceanic model, Ocean Modell., 9(4), 347-404.

Smith, T. M., and R. W. Reynolds (2004), Improved extended reconstruction of SST (1854-1997), J. Clim., 17, 2466-2477.

Walker, G. T., and E. W. Bliss (1932), World weather V, Mem. R. Meteorol. Soc., 4, 53-84.

Ware, D. M., and R. E. Thomson (2005), Bottom-up ecosystem trophic dynamics determine fish production in the northeast Pacific, Science, $308(5726), 1280-1284$.

H. Arango and E. Curchitser, Institute of Marine and Coastal Sciences, Rutgers University, 71 Dudley Road, New Brunswick, NJ 08901-8521, USA.

S. Bograd, SWFSC, NMFS, NOAA, 1352 Lighthouse Avenue, Pacific Grove, CA 93950, USA.

K. Chhak, K. M. Cobb, and E. Di Lorenzo, School of Earth and Atmospheric Sciences, Georgia Institute of Technology, 311 Ferst Drive, Atlanta, GA 30332, USA. (edl@gatech.edu)

P. J. S. Franks, Scripps Institution of Oceanography, University of California, San Diego, 9500 Gilman Drive, La Jolla, CA 92093-0218, USA

J. C. McWilliams, Dept. of Atmospheric and Oceanic Sciences, University of California Los Angeles, 405 Hilgard Avenue, Los Angeles, CA 90095-1565, USA.

A. J. Miller, CASPO Division, Scripps Institution of Oceanography, University of California, San Diego, 439 Nierenberg Hall, La Jolla, CA 92093-0224, USA.

T. M. Powell, Dept. of Integrative Biology, University of California, \#3140, Rm 3060 VLSB, Berkeley, CA 94720-3140, USA.

P. Rivière, LEMAR, IUEM Thechnopole Brest-Iroise, Place Nicolas Copernic, Plouzane F-29280, France.

N. Schneider, International Pacific Research Center and Department of Oceanography, School of Ocean and Earth Science and Technology, University of Hawaii at Manoa, 1680 East-West Road, Honolulu, HI 96822, USA. 